\title{
Arquitectura patrimonial y arqueología histórica: relaciones y proyecciones en el siglo XXI, caso Cuenca (Ecuador)
}

\section{Heritage architecture and Historical archeology: relationships and projections in the XXI century, case of Cuenca (Ecuador)}

\author{
María del Cisne Aguirre Ullauri ${ }^{1,2}$ https://orcid.org/0000-0002-3179-7839 \\ ${ }^{1}$ Universidad Politécnica de Madrid. Dirección Postal: Avenida Juan de Herrera 28040, \\ ESPAÑA. Email: cisne2222@hotmail.com - cisne.aguirre.ullauri@alumnos.upm.es \\ ${ }^{2}$ Universidad Católica de Cuenca. Dirección Postal: Calle de las Granadillas s/n. San Sebastián, \\ 010111, ECUADOR. Email: cisne2222@hotmail.com - maguirreu@ucacue.edu.ec
}

\begin{abstract}
Resumen
Esta investigación analiza los esfuerzos profesionales e investigativos para correlacionar arquitectura patrimonial y arqueología histórica. Se emplea como caso de estudio el Centro Histórico de Cuenca, segmento urbano que por sus particularidades socioculturales y por procesos locales emprendidos ostenta un amplio potencial técnico y científico para dar cuenta de la importancia de esa relación. Metodológicamente, el análisis recurre a una revisión sistemática de los informes técnicos de prospección, excavación e intervención realizados entre 2008 y 2011 por la Unidad de Arqueología Urbana (UAU) y a otros documentos técnicos y administrativos vinculantes. Para el estudio, se emplean fichas analíticas que sintetizan prácticas, relaciones disciplinares y proyecciones investigativas. Como resultado, se aprecia el bajo nivel de cohesión interdisciplinar en las prácticas, mecanismos y alcances de dicho proyecto. En efecto, la investigación en los 34 bienes se enmarca en la excavación; a su vez, la cerámica denota como el material cultural identificado y documentado; otros de origen prehispánico se han minimizado sin llegar a descartar su interés histórico. Así se concluye que los parámetros básicos, las estrategias de gestión y la socialización del patrimonio son mínimos; la arqueología ha supuesto un medio de legitimación de la intervención en entidades monumentales, y rara vez ha sido un medio para su gestión integral. La experiencia de la UAU permite identificar campos disciplinares complementarios y plantear una hoja de ruta articulada al marco profesional e investigativo para su aplicación en bienes patrimoniales con potencial arqueológico.
\end{abstract}

Palabras claves: arqueología y arquitectura, intervención patrimonial, centro histórico, excavación.

\begin{abstract}
This research analyzes professional and research efforts to correlate heritage architecture and historical archeology. The Historical Center of Cuenca is used as a case study, an urban segment that, due to its socio-cultural particularities and local processes undertaken, has ample technical and scientific potential to account for the importance of this relationship. Methodologically, the analysis uses a systematic review of the technical reports on prospecting, excavation and intervention carried out between 2008 and 2011 by the Urban Archeology Unit (UAU) and other binding technical and administrative documents. For the study, analytical sheets that synthesize practices, disciplinary relationships and research projections are used. As a result, the low level of interdisciplinary cohesion in the practices, mechanisms and scope of said project is appreciated. In fact, the approach of the 34 goods is framed in the excavation, at the same time, ceramics found denotes as the identified and documented cultural material; other of pre-Hispanic origin have been minimized without discarding their historical interest. This concludes that the basic parameters, management strategies and socialization of heritage are minimal; Archeology has been a means of legitimizing intervention in monumental entities, and it has rarely been a means of integral management. The UAU experience allows to identify complementary disciplinary fields and to propose a roadmap articulated to the professional and research framework for its application in heritage assets with archaeological potential.
\end{abstract}

Keywords: archaeology and architecture, heritage intervention, historical center, excavation.

Recibido: 23 julio 2018. Aceptado: 15 enero 2020 


\section{Introducción}

La relación histórica entre arqueología y arquitectura ha sido discutida ampliamente a nivel internacional. El emplazamiento de la ciudad andina de Cuenca, ubicada al sur de Ecuador, sumado a sus características culturales, hace impostergable ese diálogo interdisciplinar (Hicks y Horning, 2006; Vela, 2011) en el ámbito local. A ello se suma la experiencia desarrollada entre 2008 y 2011 por la Unidad de Arqueología Urbana (UAU), adscrita a la Fundación Municipal El Barranco del Gobierno Autónomo Descentralizado Cantonal de Cuenca (GAD de Cuenca) que reportó evidencia factible de análisis, discusión y construcción teórica sobre esa relación. Ciertamente, los diversos informes técnicos sobre la prospección, excavación y rescate arqueológico de edificios y espacios públicos (parques, plazas y otros) de relevancia patrimonial y no patrimonial, antes y durante los procesos de intervención para recuperación o rehabilitación (Idrovo, 2012), dan cuenta de su condición de documento histórico (Caballero Zoreda, 1995; Azkarate, 2010; Aguirre Ullauri y Álvarez, 2015), pero la formalidad administrativa ha limitado el accionar.

Estas investigaciones preliminares invitan a explorar campos poco conocidos y poco desarrollados para repensar que cualquier intervención física en el subsuelo o edificaciones existentes en las ciudades, y en la ciudad de Cuenca en particular, puedan poner en peligro de alteración o destrucción muchos de los bienes históricos que han permanecido ocultos, han estado orillados en el interior de otras obras construidas o simplemente perdidos en el propio paisaje urbano (Idrovo, 2012). Disciplinas con validez probada en la investigación y la construcción del partido arquitectónico (Vela, 2011) resultan de interés para comprender esta situación y sensibilizar al profesional sobre la compleja realidad del patrimonio arquitectónico y las inevitables limitaciones de la visión disciplinar.

Considerando lo anterior, la presente investigación busca evidenciar el diálogo interdisciplinar e incitar el despliegue de esfuerzos técnicos y científicos para la gestión rigurosa de los bienes patrimoniales. Se sirve de insumos desarrollados en el territorio como el repertorio documental de la UAU para relacionar las prácticas emprendidas según la naturaleza de los casos, las prácticas investigativas con capacidad de asociarse y las relaciones interdisciplinares factibles y pendientes; también se suman experiencias externas. El objetivo final es delinear un marco de actuación para desarrollar estudios técnicos, y efectuar propuestas de recuperación y rehabilitación de bienes patrimoniales en el Centro Histórico de Cuenca (CHC).

\section{Antecedentes}

\section{La relación arqueología-arquitectura en el contexto de América Latina}

Sin duda, un componente esencial de la riqueza cultural de América Latina es su patrimonio urbano, destacado como uno de los más interesantes de la historia urbana mundial, capaz de revelarse como un elemento sociopolítico y artístico preponderante para comprender el pasado y la actualidad de la región (Scovazzi, 1996). El desentrañar esta complejidad ha visto en la historiografía el camino más efectivo que, sin dejar de ser problemático, ha apoyado entre contradicciones diacrónicas y sincrónicas el colocar la cultura en torno a la arqueología. Si bien no es el único, su aplicación ha recuperado información sustancial que en casos como La Habana Vieja (Cuba), el viejo San Juan (Puerto Rico) y otras ciudades, ha fungido como instrumento clave para la declaratoria de patrimonio mundial (Maestre, 2012). Desde Europa, la situación que ha caminado por los mismos derroteros ha posicionado a Sudamérica en paralelo a la actividad de influencia anglosajona. La arqueología urbana ha tenido que enfrentar altibajos significativos para posicionarse; en Argentina, Uruguay y Brasil, cuyas identidades nacionales se ligan a Europa (Funari, 2015), se abrió camino con mayor facilidad, en tanto en México, Perú o Ecuador ha tenido pocos adeptos (Domínguez y Funari, 2002). En Bolivia y Venezuela, la presencia anglosajona trastocó el rumbo y la relación se encaminó más bien a la construcción de identidades sobre el esplendor de las civilizaciones prehispánicas (Zarankin y Salerno, 2007).

Este panorama mejoró a partir de 1980, cuando la arqueología histórica adquirió estatus y un programa 
de investigación propio, con ello suprimió la figura de los no arqueólogos o aficionados (Zarankin y Salerno, 2007), y la producción académica y, consecuentemente, la profesión comenzaron a proyectarse fuera de la heterogeneidad enunciada por Funari (1994, 1996 y 2002).

Como proceso coetáneo a la recuperación de los centros históricos latinoamericanos, ratificó la importancia de la disciplina a través de la abundante evidencia que salió a la luz gracias a la excavación intensiva producida tanto con miras a mejorar la comprensión de los sitios o, como en São Paulo (Brasil), Cuenca (Ecuador) y otras ciudades, para viabilizar obras y otras facilidades urbanas (Funari, 2015). Este interés permitió el rescate de artefactos $y$, con alguna frecuencia, orientó la investigación y la conectó con la historia en la medida en que ayudaba a explicar los niveles de desarrollo en cuanto al uso de materiales y otros, pero rara vez se recurrió a otras áreas como la antropología. Observando este panorama macro, según Schávelzon (2002) para el caso argentino, y según Domínguez y Funari (2002) para el caso cubano, el acometimiento integral de la arqueología histórica, y particularmente la urbana, fue constituyéndose en un tema de estudio sistemático a nivel académico y se extendió con relativa facilidad al contexto ecuatoriano.

La perspectiva arqueológica latinoamericana y su desarrollo han sido descritos ampliamente por $\mathrm{Za}$ rankin y Salerno (2007) y otros investigadores. Gracias al difusionismo, procesualismo y posprocesualismo, la disciplina se mantuvo en desarrollo y logró integrarse a la agenda de investigación de la región. No obstante, a nivel particular, la situación en Ecuador se identifica más con los albores disciplinares que con los momentos de mayor relevancia. Grosso modo, y sin considerar las compañas extranjeras, se evidencia la falta de rigurosidad en el uso de técnicas e instrumentos científicos de asistencia y otros problemas relacionados con la asignación presupuestal pública o privada. Hay que reconocer, por tanto, que la arqueología urbana no se ha consolidado, sino que su relación con la historia local o la arquitectura apenas se ha iniciado y ni hablar de campos como la arqueología militar, de plantaciones, industrias, minas y semejantes, o de la aplicación de herramientas teórico-metodológicas como la construcción tipológica, el correlato material y el modelamiento teórico-conceptual. En este sentido, el principal interés de este estudio es observar las ciudades y la arquitectura (y en el futuro otras categorías patrimoniales) con ojos diferentes de los tradicionales, es decir, tratarlas como espacios con un pasado rico y significativo que requiere ser estudiado, rescatado y preservado, y emplear la arqueología para efectuar esa visión, ya que ha demostrado ser una vía idónea para este fin (Schávelzon, 2002; Gravano, 2018).

\section{Experiencias arqueológicas en Cuenca y la perspectiva del siglo XXI}

La declaratoria del CHC como Patrimonio de la Humanidad incrementó los análisis retrospectivos, revisiones y proyecciones que se suscitaron en los segmentos legales, administrativos, académicos, profesionales y ciudadanos. Hoy, a las puertas del vigésimo aniversario, la dinámica se mantiene y encuentra soporte en diversos intereses.

La Constitución de la República (2008) regula el tema, como se deja entrever en los artículos 3, numeral 7; artículo 264, numeral 8 y artículo 379, numeral 2, que definen, respectivamente, la protección y conservación del patrimonio; la proyección en lo microterritorial, con la asignación de la competencia a los gobiernos locales, e inserta los componentes natural y paisajístico con valor histórico, artístico, arqueológico, etnográfico o paleontológico, como dimensiones de igual importancia. El Código Orgánico de Ordenamiento Territorial y Descentralización (COOTAD) (2011) ratifica lo anterior en su artículo 57, literal a). Si bien la separación disciplinar es clara, se entiende el patrimonio en su diversidad y complejidad, pero se limita la proyección investigativa.

A posteriori, otras acciones enfocadas en el fortalecimiento legal e institucional han generado instrumentos estratégicos como el Plan de Desarrollo Nacional (2007-2010), el Plan Nacional del Buen Vivir (2009-2013 y 2013-2017) y el Plan Nacional de Desarrollo Toda una Vida (2017-2021), que enfocan sus esfuerzos en ejes amplios: buscan la recuperación integral del patrimonio cultural y 
natural, la gestión y promoción de la diversidad, el intercambio y el crecimiento de la memoria social. Destacan puntualizaciones sobre el aprovechamiento del potencial interdisciplinar para la consecución de metas y objetivos tales como la promoción del conocimiento patrimonial desde la investigación, valoración, control y difusión. Se incluye también la incorporación de políticas públicas, planes, programas y proyectos (Senplades, 2007, 2009), la recuperación del patrimonio arquitectónico como política de mitigación al problema de la vivienda, la revalorización del patrimonio edificado y la protección de sitios arqueológicos y las prácticas culturales locales y el reconocimiento de la arquitectura de distintas épocas y orígenes (Senplades, 2009, 2013) hasta la importancia de su presencia en el paisaje y la investigación arqueológica. No en vano Querol y Castillo (2012) indicaron que todo el patrimonio cultural puede ser objeto de estudio arqueológico. Este panorama también es concomitante con medidas históricas tomadas en el país; casos concretos son el Decreto Ejecutivo 816 del 21 de diciembre de 2007, el Proyecto de ciudades emblemáticas (Ministerio de Cultura y Patrimonio, 2014) o el Decreto 1004 del año 2016, cuya finalidad fue la reconstrucción y reactivación productiva posterremoto, catástrofe natural que evidenció la vulnerabilidad del patrimonio cultural y las limitaciones para acometer medidas emergentes por parte de los gobiernos descentralizados y las entidades privadas.

En Cuenca, además de su ratificada singularidad (Mancero, 2010), destacan otras particularidades como la creación de la segunda UAU del país, ${ }^{1}$ en articulación con los programas territoriales. Resulta coyuntural para la gestión y materialización de proyectos pioneros de recuperación urbana y edilicia con componentes arqueológicos que, en el $\mathrm{CHC}$ coinciden también con el período de transición entre la Ordenanza para el Control y Administración del Centro Histórico (1983) y la Ordenanza para la Gestión y Conservación de las Áreas Históricas y Patrimoniales (2010). En ambos casos se abarcan las dimensiones patrimoniales arquitectónica y arqueológica desvinculadas, aunque entendidas como parte del legado

1 La primera se había formado en 2000 gracias al Fondo de Salvamento del Patrimonio Cultural de Quito (FONSAL). cultural. De hecho, el artículo 15 de la Ordenanza (2010) norma la obligatoriedad de emprender estudios interdisciplinarios (históricos, antropológicos, arqueológicos, urbano-arquitectónicos, ingenieriles) que justifiquen la intervención urbana; sin embargo, no existen referencias al segmento arquitectónico.

De esa forma, se ha venido rezagando la posibilidad de estudio y comprensión de este tema; por ello, las acciones de investigación desarrolladas por la UAU son de transcendencia, si bien luego de su extinción no se ha hecho más que dar continuidad a los aportes en parques arqueológicos y la práctica de la excavación. En el caso de la arquitectura patrimonial, y sin considerar la coexistencia interdisciplinar, la visión de su puesta en valor también destaca históricamente en el contexto nacional. Especial atención recae en el siglo XX y XXI, sobre la base de la denominada estrategia de distinción (Mancero, 2010), cuyo culmen se alcanzó entre 1977 y 1987 con la Década Dorada (Kennedy, 2007). De este período se mantienen buena parte de prácticas y criterios, así como la orientación normativa para regular y apoyar las acciones de conservación de la urbe y su legado de Patrimonio Cultural del Ecuador (1982) y Patrimonio Cultural de la Humanidad (1999). Desde entonces, sin olvidar la actividad pionera de Hernán Crespo Toral, Jaime Palacios o Patricio Muñoz Vega, suceden una diversidad de ejercicios de documentación, elaboración de proyectos de recuperación, investigación bibliográfica y capacitaciones, ${ }^{2}$ a todo nivel, pero la mirada hacia lo arqueológico-arquitectónico mantuvo bajos niveles de atención.

En todo caso, la narrativa diacrónica destaca como única la actividad de la UAU en el momento de emprender proyectos. Puede exceptuarse la labor investigativa de Ross Jamieson quien, entre 1993 y

2 Entre 2004 y 2005, la Maestría en Estudios para la Conservación de Monumentos y Sitios impartida en Cuenca aportó un reducido número de profesionales del área a la ciudad, mientras que otros se capacitaron en el exterior y configuraron la élite que gestiona reconocimientos determinantes. Lo mismo hizo la Maestría en Conservación y Gestión del Patrimonio Cultural Edificado, que inició en 2013 y continuó en 2016 y 2018. Lo lamentable es la escasa disponibilidad de arqueólogos y su dificultad para traspasar las fronteras disciplinares teóricas y prácticas. 


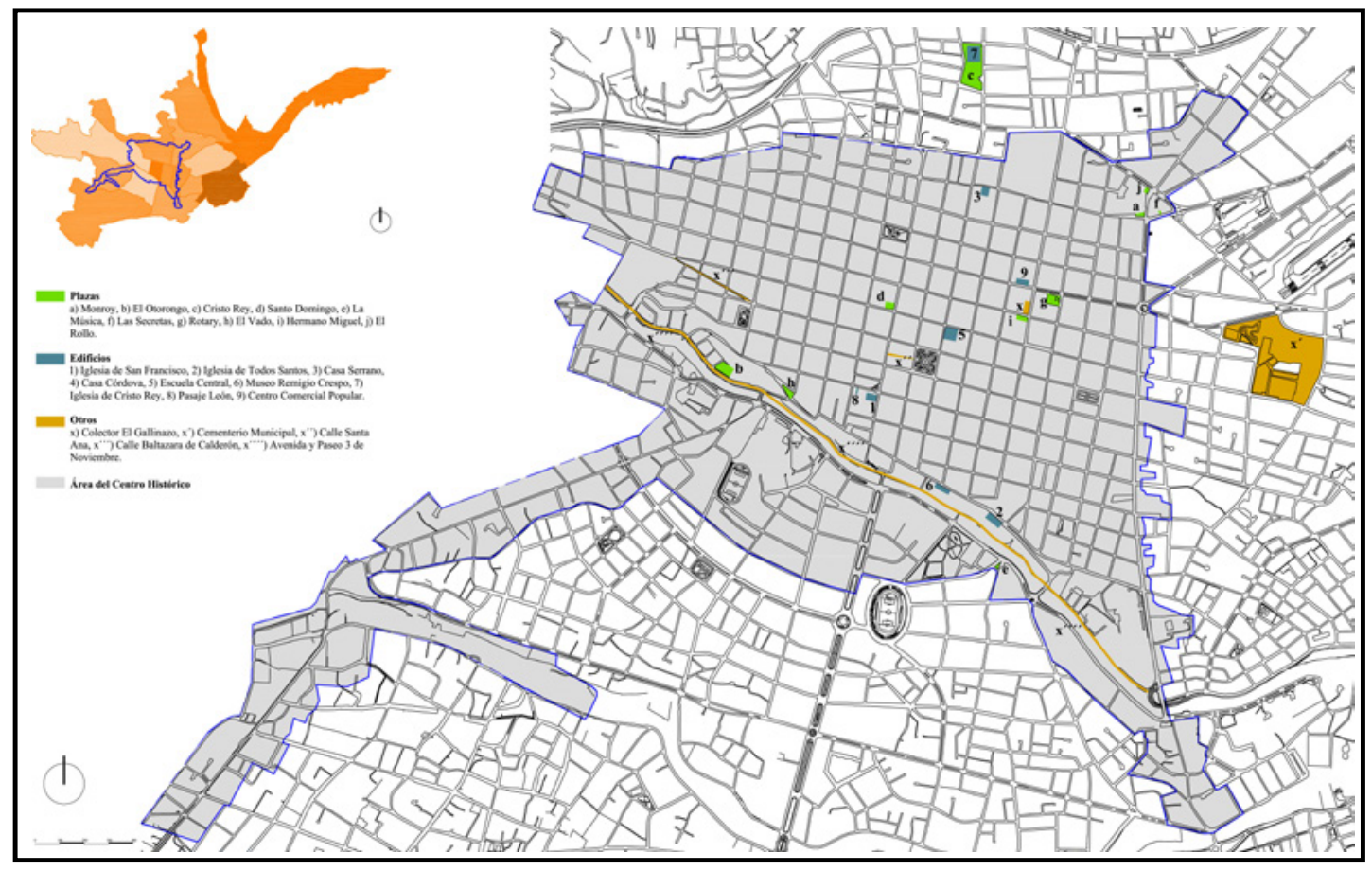

Figura 1. Casos de estudio. Fuente propia.

1994, desarrolló estudios de arquitectura dentro y fuera del CHC mediante el método del patio trasero para conocer las relaciones sociales entabladas en la Colonia, período histórico de la ciudad, desde la perspectiva interdisciplinar. ${ }^{3}$ Esta actividad académica que se sistematizó hacia 2008 (16 años después de realizada y cinco de publicada) desató el interés local por generar conocimiento arqueológico sin éxito notorio. Parecía entonces que la labor de la UAU era la lógica continuidad de las aspiraciones locales, sin embargo, fue una iniciativa que tampoco prosperó.

3 Jamieson se mantiene como investigador activo en bienes de interés patrimonial de la Sierra ecuatoriana. Zarakin y Salerno (2007) destacaron su actividad en el estudio de ciudades españolas en América del Sur. En el territorio ecuatoriano son notables sus aportes sobre la vivienda cuencana, y los complejos y edificios de tipo hacienda en Chimborazo; estos trascienden de la naturaleza estilística arquitectónica y se articulan con el análisis del paisaje, interactúan con la problemática social y la gestión de la arquitectura histórica, su recuperación y valor social. Otros investigadores extranjeros también han desarrollado aportes arqueológicos en la geografía ecuatoriana; sin embargo, la mayoría se mantienen alejados del componente arquitectónico.

\section{Metodología}

Esta investigación abarca el análisis de 24 unidades patrimoniales y al menos una decena de no patrimoniales (Figura 1) a través de los informes técnicos asociados. El proceso incluye segmentos procedimentales específicos tales como la identificación y lectura exegética ${ }^{4}$ del repertorio de informes de la actividad profesional de la UAU entre 2008 y 2011, lo cual da paso a discriminar entidades según las categorías de valor asignadas en las ordenanzas vigentes. En todos los casos se buscó acceder a los informes completos, pues no siempre se dispuso del material en su totalidad, ya que era probable encontrar información de relevancia en el contexto de interés. Se incluyó también el estudio de fuentes complementarias como la comunicación oficial interinstitucional e interdepartamental (oficios,

4 Los informes se elaboraron sobre (9) edificios patrimoniales, (2) edificios en general, (4) vías, (1) vía y (2) puentes con representatividad histórica, (2) pasajes peatonales, (1) escalinata, (12) espacios públicos tipo plaza, parque, plazoleta y semejantes y (1) espacio público en general. 
permisos y solicitudes), estudios arquitectónicos, normativa nacional e internacional y otros escritos sobre el contexto.

A continuación, para cada caso se elaboraron fichas analíticas que recogen información común de prácticas de exploración y rescate arqueológico, material cultural, necesidades investigativas desarrolladas o requeridas y el nivel de documentación aplicada. En la última etapa se definieron categorías de relación de acuerdo con las similitudes y posibles relaciones. Estas a su vez se canalizaron en torno a dos intereses específicos: los objetos de estudio y las relaciones interdisciplinares (investigativas y científicas) de los bienes patrimoniales. Como medio de interrelación se usaron los procedimientos, enfoques y resultados obtenidos en cada caso, así como las proyecciones advertibles. Finalmente, para la evaluación de la experiencia profesional se recurrió a la cuantificación de los parámetros básicos del proceso de trabajo en arqueología, las estrategias para la gestión y la socialización del patrimonio (Zafra de la Torre, 1996, 2017; Barreiro, 2012; Criado-Boado y Barreiro, 2013).

\section{Resultado y discusión}

En términos jurídicos, las modificaciones y ampliaciones que desde la Ley de Patrimonio Cultural de 1978 se producen en la Ley Orgánica de Cultura de 2016 representan para la investigación arqueológica y otros campos propios de los asentamientos históricos, como la arquitectura, antropología y otras disciplinas, un aporte sustancial y esperanzador. Supera las dificultades del Reglamento General (1984) expedido mediante Decreto 2733 y enunciado por Valdez (2012), cuando conduce hacia la sintonía con la normativa internacional (Vela, 2015), augurando con ello mejoras notables en su estudio.

En otro aspecto, el considerar recomendaciones como la organización de congresos, seminarios o talleres, la promoción de intercambios internacionales y la mutua asistencia técnica y científica (Consejo de Europa, 1992; UNESCO, 1956, 1990) significa avanzar y rebasar las formas territoriales de ver e investigar en amplitud, atendiendo la relación arqueología histórica-arquitectura patrimonial, su visión participativa desempeńa un rol clave. También el análisis de los materiales de construcción, de las implicaciones de su deterioro o alteración (Carta de Noto, 1968), así como la relación entre los diversos espacios urbanos, edificios, áreas verdes y libres (Carta de Washington, 1987), los criterios de conservación integrada (Carta Internacional para la Gestión del Patrimonio Arqueológico, 1990) y tantos otros aspectos vinculados que permanecen esquivos resultan ideales para ampliar el horizonte histórico en la esfera científica.

\section{De los objetos patrimoniales}

La actividad arqueológica profesional usa íntegramente la excavación del subsuelo bajo el procedimiento de trazado en paralelo de cuadrículas $(2 \mathrm{x} 1$ $\mathrm{m}),{ }^{5}$ aspecto que se prioriza para proceder (Idrovo, 2008, 2009, 2010; Idrovo y Bacacela, 2008a, 2008b; Idrovo y Calderón, 2008a, 2008b, 2008c; Idrovo, Calderón y Proaño, 2008; Idrovo y Campoverde, 2008; Idrovo y Guamán, 2008a, 2008b, 2008c, 2008d, 2008e; Idrovo y Maldonado, 2008a, 2008b, 2008c, 2008d, 2008e, 2008f; Idrovo y Proaño, 2008; Idrovo y Sancho, 2008, 2010).

$\mathrm{Al}$ tratarse de un único equipo profesional y disciplinar, la aplicación procedimental se asumió como práctica convencional, incluso con supremacía sobre otras como las establecidas en la Carta Internacional para la Gestión del Patrimonio Arqueológico (1990). En este sentido, el componente arqueológico se presenta como un medio para viabilizar el proyecto arquitectónico o urbano, no sin dificultades, aunque con mínimas exigencias e incidencias.

El ejercicio de recuperación organizada de los materiales arqueológicos es suficiente per se para generar conocimiento histórico (Alberto, 2008), pero además es el punto de inflexión en el que se detiene la labor, si bien se reconoce la importancia del material cultural en los espacios públicos y del material constructivo y decorativo en los edificios. Esta situación también se avista en la construcción de obras civiles petroleras nacionales (Vélez, 2012) y faculta caracterizar el escenario de la producción arqueológica,

5 Idrovo (2008) señaló que la metodología aplicada ha sido poco empleada a nivel nacional, y reconoció la existencia de dificultades y vacíos. Aun así la destaca con base en su experiencia desde los años ochenta. 
así como el perfil profesional operante (Figura 6). Esta información conforma un repertorio capaz de integrarse a la base de datos del Proyecto Arcal $^{6}$ del cual el Ecuador es miembro desde 2007. Este escenario coadyuvaría a mitigar un segmento, aunque pequeño, de la problemática enunciada por Segarra (2016) sobre las deficiencias en gestión de la información y mejoraría los sistemas de intercambio; también ayudaría en la realización de estudios comparativos (Gilabert y Mora, 2014), y en el estudio tanto del $80 \%$ de los tiestos recuperados entre 2008 y 2010 (Idrovo, 2012) como del material arquitectónico constructivo o decorativo almacenado (Figura 6) luego de las campañas de excavación.

Casos concretos como el edificio del Pasaje León, complejos de abordar en campo según Idrovo (2008b), delinean un escenario ideal para la caracterización de materiales. Lo propio en el edificio de la Casa Museo Remigio Crespo Toral, más cuando el ente rector de la gestión arqueológica dispone la cuantificación o propuesta de análisis del material histórico como una de las particularidades arquitectónicas del edificio. ${ }^{7}$ No menos importantes son otros vestigios de prácticas constructivas que se describen. De esta manera es explícita la necesidad, mas no la ejecución, en algún grado comprensible, toda vez que la implementación efectiva del Laboratorio de Química y Análisis data de 1996, la creación del Centro de Investigación del Patrimonio y la Memoria del 2015, y otros espacios técnicamente equipados se encuentran distantes. Si bien desde décadas anteriores han existido laboratorios universitarios equipados, el desarrollo investigativo sobre el patri-

6 El Acuerdo Regional RLA8043 dio origen al proyecto Arcal (2007) para promover el uso de técnicas analíticas nucleares y el desarrollo de bases de datos para la caracterización y preservación de bienes del patrimonio cultural nacional. El Ecuador participó en esta iniciativa junto con Argentina, Brasil, Chile, Costa Rica, Perú y México. A través de la base de datos es posible acceder a los resultados del análisis de muestras arqueológicas, y también a información arqueológica existente (Pla, 2017).

7 Dicho particular se incluye en el Oficio 171-SRA-08, de fecha 10 de julio de 2008 remitido por el director del INPC. Regional 6, Joaquín Moscoso al arqueólogo Idrovo. A la fecha no se determina la realización de tales estudios, al no incorporarse a informes o encontrarse como cuerpos externos. monio material se ha limitado a las campañas extranjeras, u otras áreas.

Por su parte, la contextualización y conformación del inventario y catastro de inmuebles y sitios de valor arqueológico en el Centro Histórico de Cuenca (2008) supuso una aproximación piloto (4843 inmuebles de interés) aún mayor y más ambicioso proyecto investigativo propio del área, que también quedaría inconcluso, pero que logró exponer el potencial arqueológico de diversas entidades patrimoniales (Querol y Castillo, 2012) dentro y fuera del CHC. El alcanzar casos singulares como la desaparecida Casa de Hacienda Serrano, otrora localizada en el predio del Centro de Rehabilitación Social Regional Sierra Centro Sur, o el mutilado Conjunto Urbano Arquitectónico de Cristo Rey de Cullca, ratifica su impacto interdisciplinar y territorial.

A nivel particular, desde la muestra arquitectónica patrimonial se evidencia el cumplimiento de estudio arqueológico en contextos históricos planteado por los artículos 30 y 63 de la Ley de Patrimonio Cultural (1978), sin embargo el procedimiento se limitó a la exploración previa a la intervención, o al rescate y documentación del material cultural, en consonancia con la dinámica nacional. En edificios como la iglesia de Todos Santos y la Escuela Central se logró el tratamiento museográfico de los hallazgos, y en casos como el antiguo colector El Gallinazo, ${ }^{8}$ al menos se sugirieron. Otro caso de estudio es el edificio del Pasaje León, en donde la investigación arqueológica desconoce cualquier posibilidad sobre la cota 0 , pese a singularidades arquitectónicas de interés. Asimismo, el trabajo interdisciplinar planteado y que pretende, a juicio de Idrovo (2008a), evitar la tergiversación o falsear la identidad histórica y cultural y mantener la noción de valor patrimonial sustentada en el estilo arquitectónico, no supera el umbral de la recomendación, considerado por Zafra de la Torre (1996) como el nivel más pedestre de la disciplina. En el resto de edificios se repite la práctica sin variaciones significativas, e incluso podría inferirse como

8 El interés por recuperar las piezas de bóvedas y bases de piedra con fines didácticos o museográficos, acorde con los principios internacionales reconocidos desde tiempo de Boito, reposan en el Oficio 0111-SRA-08 de fecha 26 de mayo de 2016, remitido por el director del INPC, Regional 6. A la fecha no se ha concretado su ejecución. 


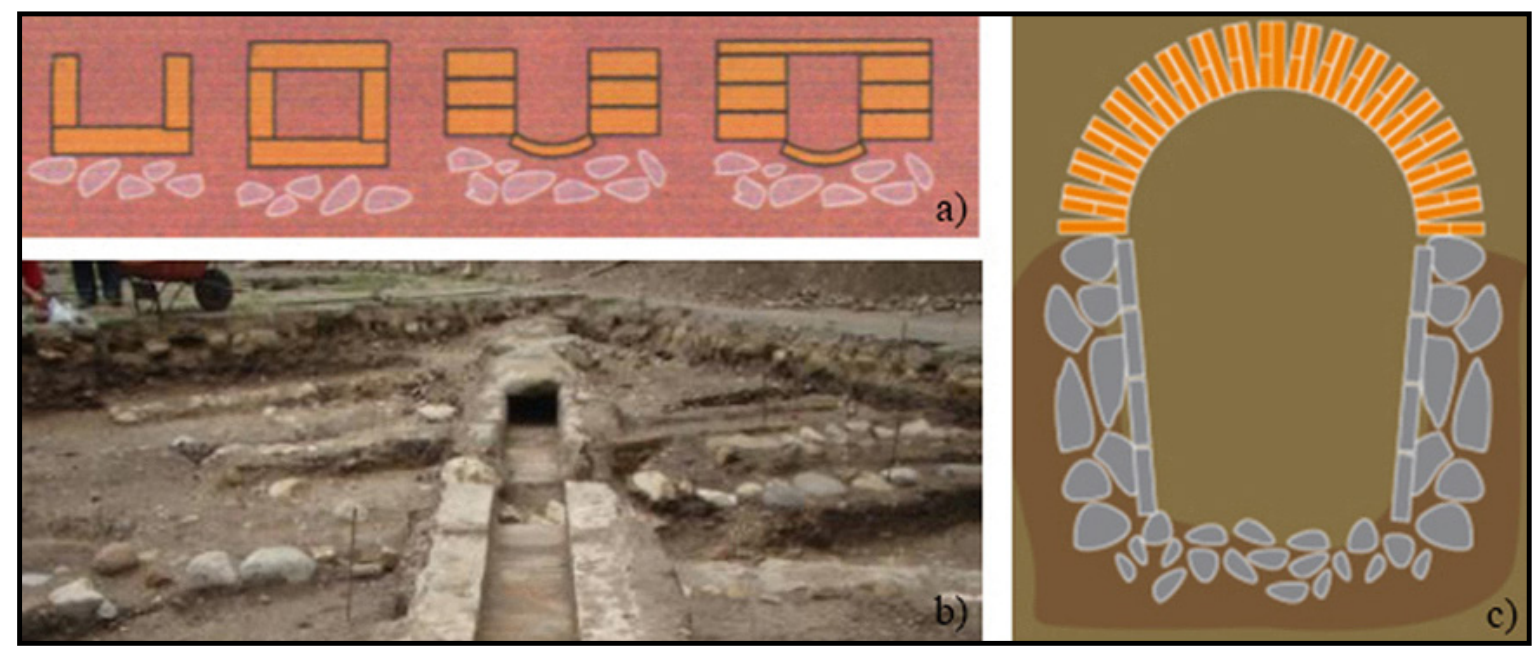

Figura 2. a) Tipos de canales identificados por la UAU. Fuente: Guamán 2011. b) Red de canales. Fuente: Idrovo 2009. c) Corte-perfil del colector de tipo abovedado y fondo plano registrado en la calle Manuel Vega. Fuente: Idrovo, $2008 \mathrm{a}$.

consecuencia estructural de la labor, direccionada a inmuebles y espacios de destacado reconocimiento patrimonial según las Ordenanzas de 1983 y 2010, que segrega y minimiza el potencial de otros bienes como parte de los mismos procesos históricos.

De ello, las investigaciones no reflejan contraste efectivo entre fuentes documentales u orales, pese a la expresa necesidad indicada por Idrovo y Bacacela (2008c), y pese también a su propia naturaleza (Zafra de la Torre, 1996); un caso singular es la calle Santa Ana, mientras que en lo general, al hablar de vestigios culturales provenientes de objetos utilitarios o muebles e inmuebles, se omite la investigación analítica, o documentación tipológica, que en el caso arquitectónico aporta a la microhistoria del edificio y apoya la construcción del partido intervencionista. En la Escuela Central (Idrovo, 2009), destaca la variedad de tecnologías utilizadas; algunos elementos, seguramente pétreos y asociados a los canales de piedra del patio, mantienen la huella de lo inca, y en la iglesia de Todos Santos se habla de reaprovechamiento de materiales de infraestructuras previas (Idrovo y Guamán, 2010, citando a Arias) (Figuras 2a y 2b), lo que deja la duda de su presencia más allá del subsuelo. En la iglesia de San Francisco, ${ }^{9}$ por su parte, el

9 Idrovo y Calderón (2008) indicaron que en muros, columnas, pedestales y otros elementos arquitectónicos se ha reutilizado material pétreo, posiblemente de origen análisis constructivo de muros y paredes de adobe y bahareque, al igual que la indagación sobre su antigüedad, han constituido un buen indicio para la posible vinculación del sitio con ocupaciones más antiguas (Idrovo, 2008a).

De este modo, es posible ratificar que, pese a posibles segregaciones, en todas las edificaciones, incluso en las humildes, se pueden identificar diferentes fases constructivas a partir del conocimiento de sus muros, y con ello se puede develar esa parte de la ciudad escondida y olvidada (Idrovo, 2008a). Sin embargo, los informes técnicos solo describen en términos generales insumos relevantes para este fin, como los materiales del segmento arquitectónico y los estratos geológicos; se usan denominaciones como tierra amarilla o cascajo para posibles morteros, o cal de color ladrillo o enlucido del ladrillo con cal para revestimientos (Idrovo, 2009). El abundante material de piedra, ladrillo y teja localizado no reporta registro de identificación, descripción o caracterización; acaso la hipótesis de su pertenencia a un edificio previo, como sucede en la escuela Central o la iglesia de San Francisco (Idrovo, 2009; Idrovo y Calderón, 2008b), corrobora las falencias al valorar el potencial documental de la evidencia arquitectónica.

inca; sobre esto y considerando la abundancia documental, sostienen como innecesaria la prospección con alcance a otros edificios. 
Como hallazgo fundamental destacan las bóvedas que conforman un mausoleo subterráneo en el Cementerio Patrimonial. Pese al limitado tratamiento y profundidad, se exhiben indicios de análisis paramental en el alzado frontal para identificar al menos cuatro etapas constructivas (Idrovo, Calderón e Idrovo, 2008). Sobre el origen de los materiales empleados, la descripción se ratifica como limitada y resulta difícil su determinación o contextualización histórica, ya que la fabricación de los materiales ha cesado y no se cuenta con un registro o historial sobre su elaboración. Como consecuencia, la documentación de calidad se centra en el material cultural cerámico y las osamentas. En otro caso, el informe de prospección de la Casa Serrano, antigua fábrica de sombreros, la describe en términos arquitectónicos desde los materiales (Idrovo y Maldonado, 2008e), sin mayor alcance. De la excavación en los patios se identifican pavimentos con base en la disposición variada de piedra de río, mientras se incide en la abundancia de restos cerámicos de tipo ladrillo y teja, sin llegar a mayor especificidad técnica o científica.

En las prospecciones a los edificios no patrimoniales, la evidencia cultural ratifica la presencia de material de interés como cimientos de filiación inca. En la vivienda de Pedro Córdova se recuperaron fragmentos vidriados y no vidriados (Idrovo, 2008a) también reconocibles en edificios patrimoniales. En el ejercicio sobre el Centro Comercial Popular se identificaron vestigios de un canal destruido (Idrovo y Campoverde, 2008), también presente en edificios patrimoniales fuera del área histórica, como la Casa de Hacienda Serrano Lofruscio. ${ }^{10}$

Por su parte, el caso de los espacios públicos es análogo al arquitectónico, se ratifica la observancia normativa, pero la investigación de naturaleza arqueológica se centra en el estudio de los materiales culturales que ayudan a determinar su razón social (Idrovo, 2008c); asimismo está limitado por la

10 Por su composición morfológica, el inmueble pertenece al selecto grupo de complejos hacendarios de la provincia del Azuay (INPC, 2008). Sin descripciones arquitectónicas vinculadas, Villalba (2010) describió la prospección del terreno, mientras la autoridad patrimonial ejecutó lo propio desde la vertiente morfológica, estética y funcional. inexistencia de la documentación original y archivos auxiliares. En el mencionado colector El Gallinazo, la evidencia material destacada en términos constructivos y estéticos es propicia para la investigación científica (Figura 2c). Recaen en esta condición las infraestructuras que se extienden hasta la Plaza Rotary. Idrovo y Proaño (2008b) destacan elementos para la distribución del agua, pavimentos de ladrillo y canto rodado, muretes de piedra y abundante material cerámico. En ningún caso se profundiza el estudio.

En las calles Santa Ana y Baltazara de Calderón, los hallazgos del canal y elementos semejantes y un antiguo horno (Idrovo y Sancho, 2008b) se documentaron de manera gráfica y fotográfica, y se contextualizaron a partir del relato histórico, esto es, la construcción de la desaparecida iglesia de la Compañía de Jesús y las disposiciones del gobernador Vallejo (Idrovo y Bacacela, 2008c; Idrovo y Sancho, 2008b). En la calle Santa Ana, el criterio sustancial para el proyecto de intervención fue la suma de elementos de valor histórico-arquitectónico propio de la imagen que se quiere proyectar de la urbe (Idrovo, 2008; Idrovo y Bacacela, 2008c) y con ello se apertura el riesgo potencial de pérdidas materiales.

En el estudio de otros espacios públicos la investigación arqueológica expuso que en sitios como el Otorongo predomina un material de época colonial y moderna (Idrovo y Guamán, 2008a). En la Plazoleta de la Música, Joel Monroy, Las Secretas y El Rollo se evidencian diversos tipos de pavimentos de ladrillo, piedras de pequeños tamańos y extraordinariamente alguna infraestructura tipo canal de agua (Idrovo y Maldonado, 2008a, 2008c; 2008d; Idrovo y Guamán, 2008f). En la plazoleta de El Vado se incluyen modernos graderíos de piedra con alguna evidencia inca, un muro de piedra y cal, troneras de piedra, un pequeño puente peatonal de ladrillo y cal y una banca circular (Idrovo y Maldonado, 2008a) (Figura 3). En la plaza Hermano Miguel, Pasaje Gran Colombia y Pasaje Hermano Miguel (Idrovo y Sancho, 2010), el material cultural destacable se remonta a la época republicana, mientras lo inca o cañari es escaso. En la plazoleta de Santo Domingo, junto al segmento de canal inca, como en la Escuela Central, se identificaron osamentas humanas (Idrovo y Calderón, 2008c). En ningún ejercicio se 


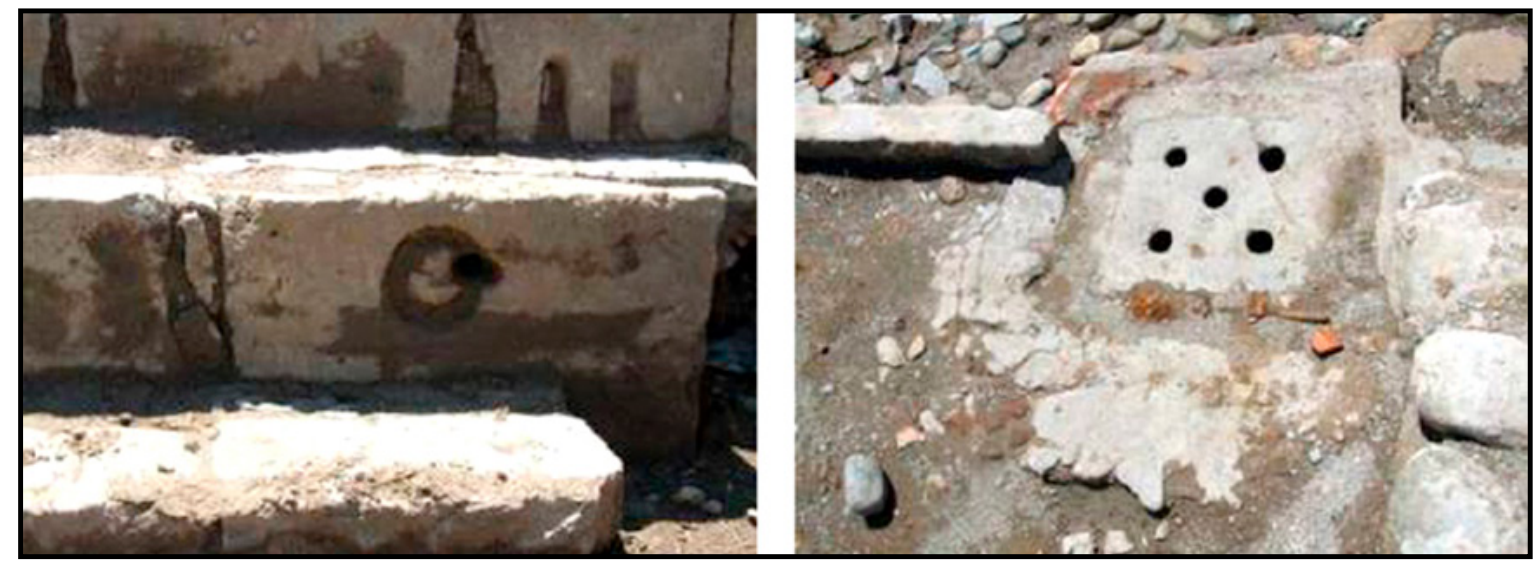

Figura 3. Hallazgos en la Plazoleta de El Vado. Fuente: Idrovo y Maldonado, 2008.

superó el nivel documental y descriptivo, ni se observó el vínculo con el objeto arquitectónico.

En grupo final de casos de estudio, calles y pasajes sin valor patrimonial, la práctica investigativa se mantuvo y el enfoque fue el salvamento de los vestigios que pudieran hallarse durante la renovación y mejoramiento de infraestructura. Este fue el caso de la Avenida y Pasaje 3 de Noviembre, calle Pío Bravo y Manuel Vega. Sobresale la infraestructura de la plazoleta de El Vado, la cual Idrovo y Maldonado (2008a) describen como una vía.

En este concierto, la falta de continuidad en la actividad arqueológica y la aplicación del Inventario y Catastro de inmuebles y sitios con valor arqueológico localizados en el CHC (2008) derivan en pérdidas materiales. La importante cantidad de intervenciones e infracciones ${ }^{11}$ que anualmente se realizan, particularmente en el ámbito privado, lo evidencian: no siempre están bajo la dirección de un profesional calificado, y tampoco se prevé la elaboración de estudios arqueológicos (Carta de Venecia, 1964). En este sentido, es menester retomar la propuesta de Idrovo (2008a) que sostiene con contundencia que las huellas físicas del proceso histórico, aunque trascienden lo meramente material, superan su depo-

11 Entre 2005 y 2014 se cuantificaron 1041 infracciones concentradas en el área próxima al núcleo central, de ellas al menos la mitad corresponde a edificios con valor patrimonial definido, y destacan las acciones vinculadas a la falta de permisos de intervención. Para ampliar ver García (2015). sición en el subsuelo y es posible su identificación, aun en segmentos mínimos a nivel de los muros, en especial en la arquitectura doméstica que evita el criterio tradicional de representatividad (Zafra de la Torre, 2017). Los edificios localizados en la calle General Torres y Mariscal Sucre, y los situados en la calle Padre Aguirre y Gran Colombia, lo ejemplifican. En ambos casos los muros exponen muestras representativas de material pétreo de potencial relevancia histórica. Podría entonces replantearse el proceso histórico arquitectónico y constructivo acontecido en la urbe, con base en la existencia de muestras aún desconocidas en preexistencias arquitectónicas de diferentes características propias de la riqueza de conocimiento de la ciudad oculta y los traumas vividos (Idrovo, 2008a), más cuando el relato histórico cotidiano tiene como eje la élite. Benedet (2012), quien abordó el asunto en Buenos Aires, lo extendió como una realidad potencial de ciertas ciudades latinoamericanas, entre ellas Cuenca (Figura 6).

En correspondencia, la dependencia bidireccional entre arquitectura y espacio público también se ve disminuida en los procesos investigativos, y con ello la posibilidad de producción de conocimiento transversal. Vale sumar a la tarea de su articulación, asimilar la noción de objeto estratificado de la arquitectura con fines investigativos, prácticos y lógicos, a fin de abandonar el paradigma violletiano con tintes boitianos de la restauración monumental (Fernández-Baca, 2014), al devolverle la naturalidad al legado arquitectónico, ratificar el aporte de los añadidos y la incidencia del tiempo. 


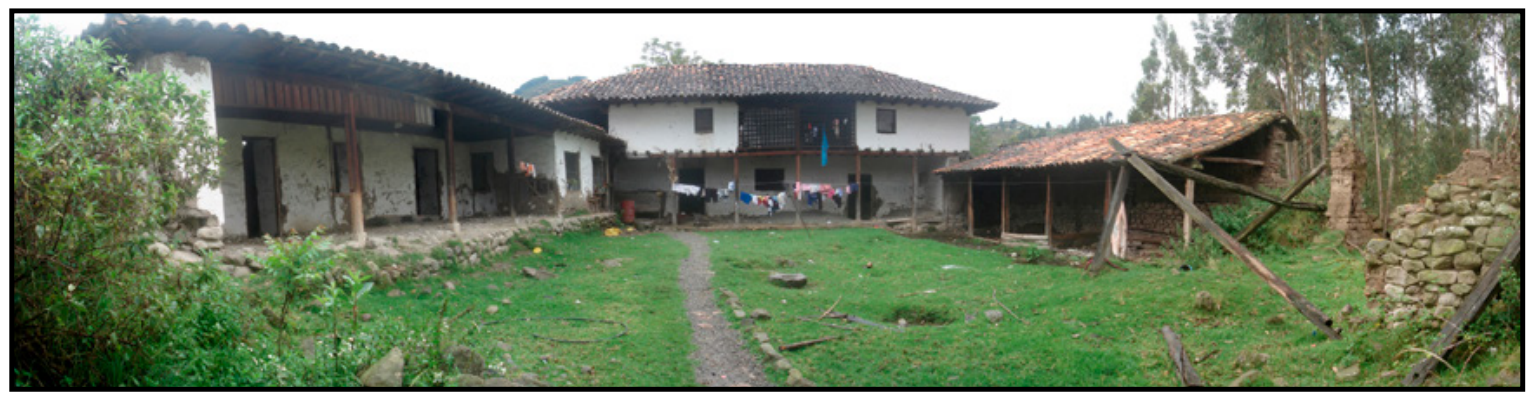

Figura 4. El complejo hacendario. Fuente propia.

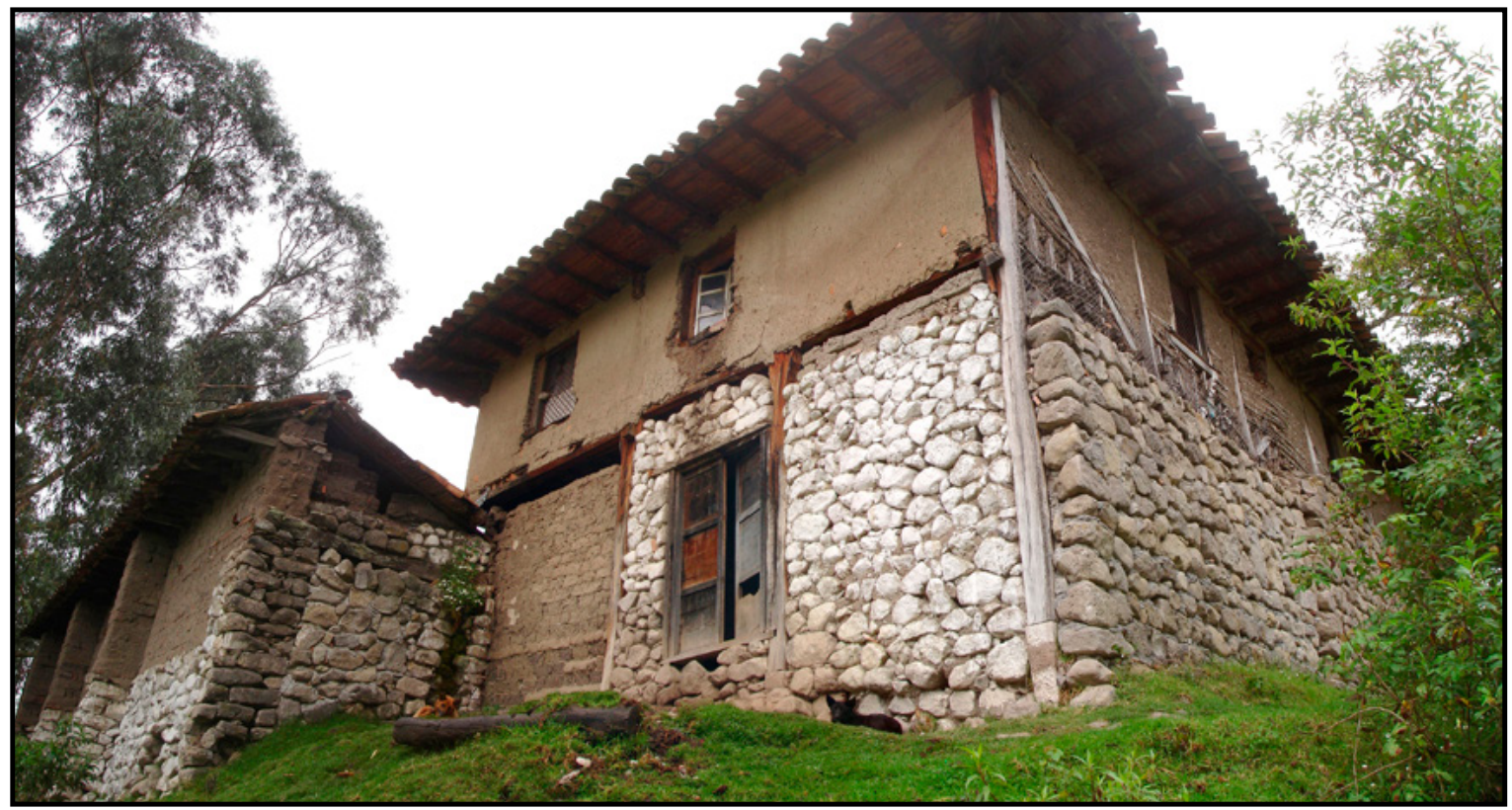

Figura 5. Vista posterior del edificio principal. Fuente propia.

En la línea, las excepciones geográficas y connotaciones singulares de la Casa de Hacienda de la Familia Serrano Lofruscio (Figura 4) abren espacio a un debate mayor, ya que sobrepasan la noción de conservación por relevancia patrimonial y avanzan hacia la condición metacultural (Criado-Boado y Barreiro, 2013) y la significancia del valor social (Astudillo, 2012; Ministerio de Justicia, Derechos Humanos y Culto, 2012) como medio que nutre la memoria colectiva (Barreiro, 2012). Esto, que derivó en la extinción física, no coincidió en el potencial conocimiento de extraer bajo la atenta vigilancia de profesionales, actores sociales y la entidad competente, aplicando las más básicas prácticas de registro (Barreiro, 2012; Zafra de la Torre, 2017). Como escenario alternativo de interés, se suscita la aplicación del método de lectura estratigráfica muraria y la caracterización de materiales de construcción para responder a múltiples interrogantes sobre la posibilidad de reutilización del material pétreo del sendero y muros identificados por Idrovo (2008a, 2010), Jaramillo (2010), Villalba (2010) y Galarza (2012) ${ }^{12}$ como parte de derivaciones del Qhapaq Nan (Figura 5). Tampoco se desconoce el potencial del estudio morfológico

12 La documentación inédita abordada incluye el Informe preliminar de inspección de la Hacienda de los Herederos del Sr. Lautaro Serrano de fecha 2 de octubre de 2008 emitido por la Dirección de Áreas Históricas y Patrimoniales del GAD Municipal de Cuenca, y, la propuesta para realizar el informe de prospección arqueológica en el sitio Icto-Cruz, Cuenca (2010), emitida por el arqueólogo Jaime Idrovo. 
de los volúmenes arquitectónicos para desentrañar las interrogantes de Carpio y Flores (1996), INPC (2008), Ministerio de Justifica, Derechos Humanos y Culto (2012) y Villalba (2011), pero ante todo la condición estratificada del edificio reconocible a través del soporte fotográfico existente (Figura 2). De este modo, se posiciona el estimar tipos de intervención excluidos de la ordenanza; tal es el caso de la anastilosis, como única opción de conservación, planteada sin éxito por la Dirección de Áreas Históricas y Patrimoniales (2009) y ratificada por Astudillo (2012) con base en la Carta de Venecia (1964).

\section{De las relaciones interdisciplinares}

Todavía persisten incógnitas históricas que la historiografía cuencana no ha respondido. Ciertamente, su resolución se traduciría en un conocimiento minucioso y reflexivo sobre los fenómenos ignorados, y contribuiría a forjar un camino hacia el autorreconocimiento e identidad del ciudadano de la región (Idrovo, 2008c). La rehabilitación como acción de recuperación física y mejoramiento estético no se ha prestado para explorar estas dimensiones capaces de concretar una aproximación integral, y levemente se ha aplicado la capacidad de reconocer la autenticidad y mantenerla con su integridad (Doglioni, 2012). Experiencias europeas y latinoamericanas evidencian que una manera de responder esas incógnitas es potenciar la articulación sistemática entre arqueología con sus diversos tipos y la arquitectura, el más marginado segmento investigativo en Iberoamérica y en el Pacífico según Vela (2011).

En este panorama, las apreciaciones derivadas de prácticas, herramientas y métodos investigativos dejan entrever que el material cultural identificado, en su más amplia connotación, no ha sido aprovechado en pro del conocimiento histórico, arqueológico y arquitectónico en tantos casos de estudio que se han tenido, o que pudiesen proyectarse con base en el nunca vigente Inventario y Catastro de inmuebles y sitios con valor arqueológico localizados en el CHC. La operatividad profesional es innegable, sin embargo no minuciosa; se ajusta a las consideraciones y prácticas técnicas y legales vigentes, lo cual denota coherencia con el ejercicio profesional, pero al margen del aporte científico.
En lo arquitectónico, no se puede hablar de relación interdisciplinar con la arqueología histórica o la urbana, ya que los trabajos se concentran en la excavación y descripción de características del material cerámico, infraestructuras menores y su contextualización referencial a sucesos del proceso diacrónico de la urbe. Corroboran lo dicho las prospecciones realizadas en espacios públicos, las cuales, pese a tener relaciones indisolubles con los objetos arquitectónicos adyacentes, se observan de forma autónoma. En este sentido, podría hablarse de una aproximación disciplinar sobre entidades patrimoniales arquitectónicas y urbanas con fines documentales y rescate conforme los procesos de modernización, mas no un aporte a la construcción teórica y práctica. Como deuda técnica del proceso se sitúa la sistematización teórico-metodológica y la formalización de los procedimientos (Criado-Boado y Barreiro, 2013; Zafra de la Torre, 2017).

Planteamientos concretos de interés son el estudio de los procesos adaptativos (tecnológicos e ideológicos) planteado por Valdez (2012) y Appetecchia, Brandt, Gardelin, Menander y Tharén (2012), quienes incorporan la noción de análisis sobre el espacio vacío contenido en los entes arquitectónicos, así como el estudio de la relación objeto/sujeto/tiempo/ espacio $^{13}$ de Beaudry y Parno (2016). Se rebasan las relaciones interdisciplinares y llega a las multidisciplinares, desde cuya perspectiva se insta con contundencia y decisión y no solo desde la experiencia de la UAU; lo propio ocurre con los trabajos de Idrovo (1993, 1998, 2000), Jamieson (2003, 2005, 2014) y las experiencias como las recogida por Buys, Domínguez y Andrade (1988), Buys, Domínguez y Zambrano $(1989,1990)$ continuadas a través de la arqueología histórica por múltiples investigadores internacionales. En suma, todo aquel conocimiento que reposa en infinidad de archivos y bibliotecas también posicionaría científicamente a la investigación arqueológica y proyectaría su incursión en nuevos segmentos capaces de brindar una aproximación integral para la gestión a largo plazo y, por tanto, a

13 Los autores consideran que incluso el movimiento de una persona hacia otra y de un lugar hacia otro impregnan la cultura material con una especie de pátina o "aura” (Benjamin, 1992), que es esencial para su interpretación contemporánea. Para ampliar ver Beaudry y Parno (2016). 
estudios integrados (Zafra de la Torre, 1996). Esto indica que en principio, es tiempo de emprender la ardua tarea de ir completando persistentemente el inventario (Valdez, 2012) y con carácter sucesivo incluir las perspectivas interdisciplinar y multidisciplinar.

Desde otro ángulo, los escenarios desarrollados y expuestos se mantienen en un perímetro controlado tal que permite construir sugerencias y recomendaciones para la intervención y recuperación patrimonial entre 2008 y 2011. No representa mérito menor la labor investigativa llevada a cabo, tampoco las advertencias derivadas frente a la inexistencia de políticas y prácticas permanentes en torno al patrimonio arqueológico de la ciudad (Idrovo, 2008a), o la aún latente necesidad de implementación de normativas y procedimientos de intervención en inmuebles públicos y privados, con base en la categorización, las demandas actuales y la ética profesional. ${ }^{14}$ Lamentablemente la aplicación no ha prosperado y persiste el vacío tanto como el desvanecimiento de los aportes, motivaciones y proyecciones.

Los problemas que indican Segarra (2016), Rivadeneira (2013) o Valdez (2012) han sido constantes en la investigación patrimonial. ¿A qué se puede aspirar entonces en este campo científico?; ‘a una permanente interacción entre el profesional y el edificio, al margen de las áreas de conocimiento o a esperar los insumos del esfuerzo extranjero para solventar las incógnitas de las que habla Idrovo y otras que surjan? Ciertamente, quedan aspectos que trabajar, si bien su abordaje conlleva riesgos, como el de fracasar con el planteamiento investigativo (Figura 6). No menos riesgoso ha sido exponer este trabajo, sin embargo ha posibilitado ratificar la cada vez más creciente urgencia de vínculo entre disciplinas, avocando desde la instancia académica la confluencia de medios y estrategias, el superar los actuales y pasivos niveles poco y medianamente satisfactorios reflejados al evaluar la actividad arqueológica pro-

14 La categorización establece tres niveles conforme las fichas de inventario: el primero, rojo o de prospección arqueológica obligada; el segundo, amarillo, de prospección recomendada, y el verde, de prospección innecesaria. Para Idrovo (2008a), en la primera categoría los hallazgos no constituyen garantía, en la segunda que se ejecute la prospección, y en la última que se identifique material de interés cultural. fesional bajo los parámetros de medios y tipos de trabajo, productos asociados y valor social. ${ }^{15}$

Como consideración final en el área, habría que anotar que el desarrollo del Inventario y Catastro de inmuebles y sitios urbanos con valor arqueológico, en la constitución de la UAU enfocada al conocimiento de la ciudad antigua (Idrovo, 2008), incluyó una diversidad de investigadores, entre ellos arqueólogos e historiadores, pero no arquitectos, y ha carecido de continuidad de los procesos de intervención e investigación arqueológica (Zafra de la Torre, 1996, 2017). Con estas reflexiones, no se pretende posicionar utopías, sino verdaderas transformaciones cuyo fin no es tampoco salvaguardar la arqueología de investigación (Alberto, 2008) de la práctica (Zafra de la Torre, 1996), sino proferir garantías de idoneidad y calidad para acometer el conocimiento histórico, social y científico desde ambos planos. Son muchos los factores que intervienen y que hace falta observar para que la gestión del patrimonio sea integral, efectiva, flexible y permita ponerlo en valor, a la vez que se convierta en un ingreso para los habitantes (Criado-Boado, 2013; AA.VV., 2015), trascienda las nociones disciplinares segmentadas; se pase de la urbe, paisaje urbano, paisaje histórico hacia la noción de patrimonio histórico arqueológico, al tratarse de una urbe en evolución, susceptible de definir capas aún no reconocibles, determinantes del crecimiento y transformación territorial, incluso entreviendo relaciones practicadas de manera inconsciente y no tipificadas (Figura 6).

\section{Del alcance de las relaciones, los resultados y las proyecciones}

A pesar de que se trató de una muestra al azar, diversa en el marco del CHC y contundente a nivel individual, las prácticas arqueológicas como estrategias de cuidado y registro (Zafra de la Torre, 2017) están restringidas al conocimiento primario, sin mayor

15 La arqueología y la arquitectura en torno al patrimonio no se limita al ámbito técnico o práctico (Barreiro, 2012; Criado Boado y Barreiro, 2013), también cumple un papel esencial en la academia porque implica la puesta en marcha de un conjunto de transformaciones educativas en los modelos pedagógicos y didácticos hacia una formación más significativa que integre saberes. 


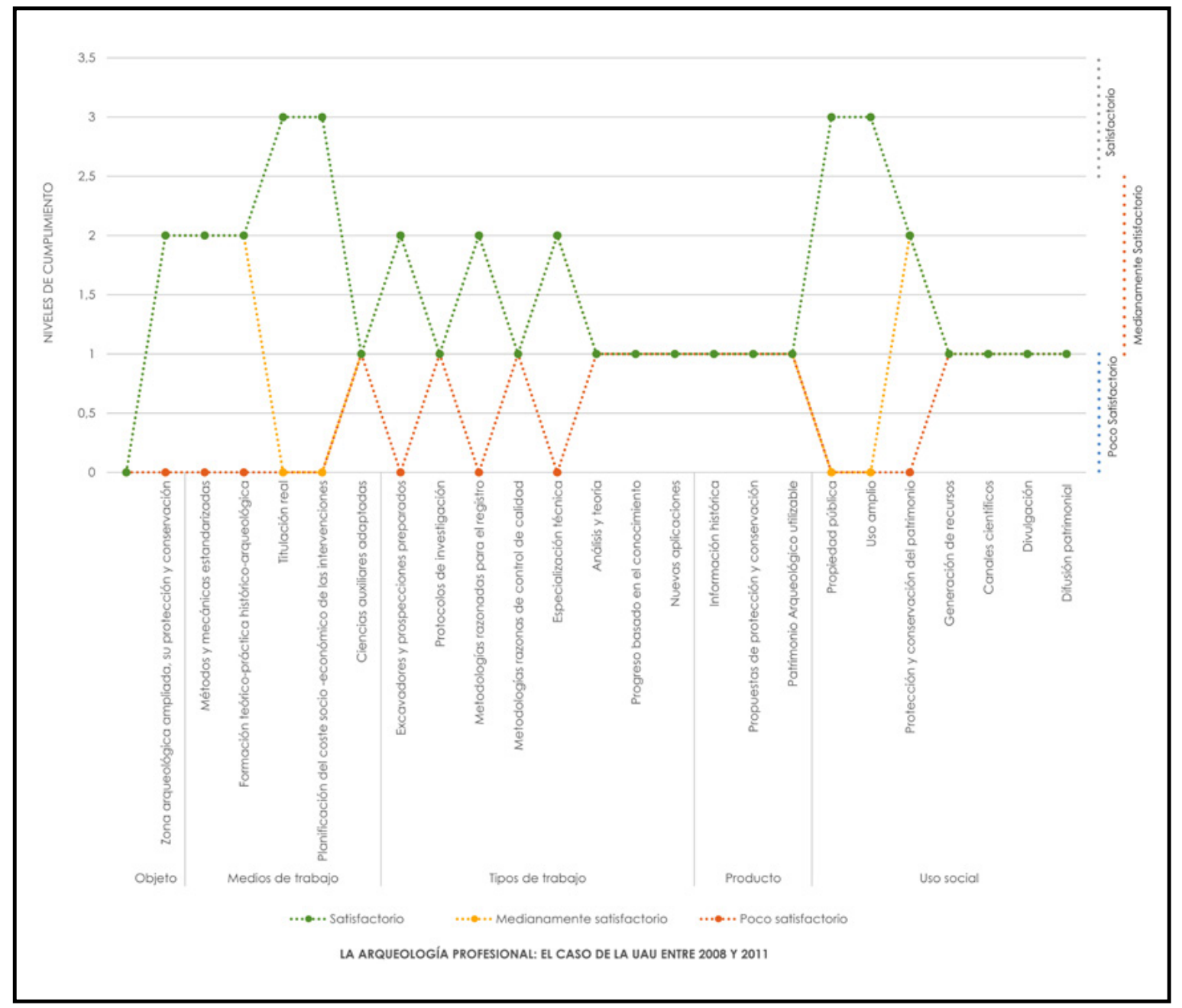

Figura 6. Diagrama de evaluación de la actividad de la UAU entre 2008 y 2011. Fuente: Zafra de la Torre, 1996 y 2017; Barreiro, 2012; Criado-Boado y Barreiro, 2013.

proyección científica. ${ }^{16}$ Esta condición puede estar determinada por el contexto administrativo, político y presupuestario al que obedece. Justamente, realizar estudios analíticos de este tipo deja latente la necesidad de proseguir investigando desde la relación arquitectura-arqueología (Figura 6).

Con la finalidad de concretar las apreciaciones sobre las prácticas, métodos y herramientas desplegados, una posible síntesis plantearía que, pese al arduo trabajo, la inexistencia de ejercicios de contraste, relación y verificación material limita su uso

16 Esta es una práctica común en otros países latinoamericanos (véase Zarankin y Salerno, 2007). como recurso para futuros estudios. Rivadeneira (2013) indicó que las interpretaciones emergidas en el seno de esta relación son limitadas y reinterpretables, pero que bien podrían ser retomadas en mejores condiciones. Asimismo, las contrariedades del proceso no desmerecen el ambicioso planteamiento de Idrovo y su equipo, quienes, aspirando a documentar la esencia de la ciudad histórica, no solo proyectan excavaciones sistemáticas, sino también acciones de valoración interdimensional, incluso proyección del futuro valor de uso social y adaptación a la contemporaneidad (Choay, 2007) de manera articulada (Figura 6). Como consecuencia, las dimensiones técnicas pendientes son múltiples y complejas, y su implementación implica un reto 
para la renovación del proyecto investigativo y profesional truncado.

Las aspiraciones institucionales y la predisposición profesional disciplinar dejan entrever que el segmento investigativo y práctico desarrollado entre 2008 y 2011 no ha mejorado. Otras prácticas son desconocidas o minimizadas. Asimismo, es extraña la figura del arquitecto-historiador, del arqueólogohistoriador como alter ego del arquitecto-restaurador, pero también del arqueólogo-arquitecto y la visión sobre la arqueología como una teoría activa del conocimiento (Zafra de la Torre, 1996), que desempeña un papel fundamental en la construcción de este nuevo proceso (Tabales, 2002). Así, la hoja de ruta para el desarrollo de estudios y documentación arquitectónica con componente arqueológico se enmarca inicialmente en el segmento profesional, al considerar que otros insumos, aunque necesarios, rebasan las posibilidades de la presente investigación. No obstante, como mecanismo de retroalimentación y adhesión interdisciplinar (Criado-Boado y Barreiro, 2013), se propende el acercamiento del caso, así como la visualización de una estructura funcional para el reporte sistemático (Figura 7). Según Valdez (2012), es una problemática general de la arqueología ecuatoriana que ha representado para el INPC la imposibilidad de procesamiento.

El enfoque recoge los lineamientos de los insumos técnicos vigentes, esto es, los Términos de referencia para la elaboración de estudios históricos en
Edificios de Valor Emergente, Valor Arquitectónico A, Valor Arquitectónico B y Valor Ambiental y el Contenido básico de anteproyectos según categoría del inmueble. En el componente arqueológico la orientación es correctiva y preventiva, intenta combatir las urgencias, sorpresas e imprevistos como los enunciados por Querol y Castillo (2012), pero también viabiliza zonas de reserva que se deben conservar. Las autoras proponen evaluar la aplicación de decisiones como: a) no estudiar y no destruir las zonas de reserva, sino dejarlas para el futuro; b) estudiar y abrir al público los restos arqueológicos; c) estudiar y conservar la evidencia sin visitas públicas; d) estudiar o documentar para luego destruir el material, y e) no estudiar y destruir (Querol y Castillo, 2012). En este sentido, la propuesta se ha organizado en etapas: investigación base (de origen, contexto o procedencia), análisis, interpretación y síntesis. Los numerales reconocimiento (1), objeto arquitectónico (2) y evaluación de potencial interdisciplinar (3) (Figura 7), corresponden a la primera instancia; estudio histórico y otros (4) y muestreo y análisis de materiales (5), al análisis e interpretación, y definición de criterios y propuesta (6), al segmento de síntesis analítica (Figura 7). A criterio de ICOM (1984), lo importante es la propuesta como medio de mejorar la habilidad para descifrar el mensaje científico y de ese modo aportar al conocimiento.

Particulares operativos como el análisis de parámetros aplicados por Parenti, Brogiolo, Caballero, Azkarate y otros deberán recoger las acotaciones

REQUERIMIENTOS ACTUALES

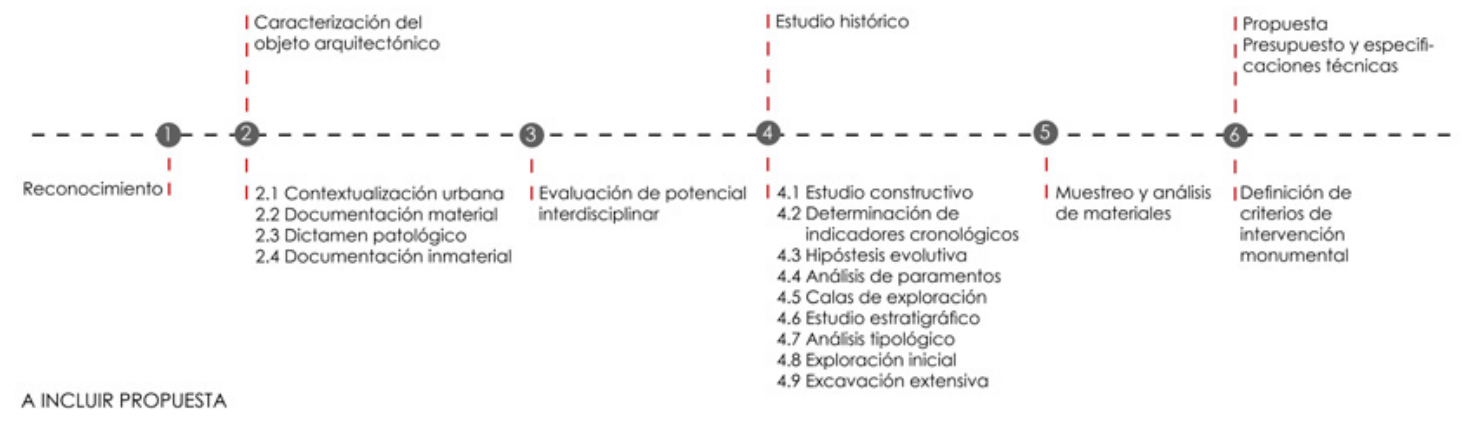

Figura 7. Articulación investigativa entre arquitectura y arqueología. Fuente propia. 
que ha sugerido Tiziano Mannoni para el caso de arquitectura de revestimientos múltiples, y deberá debatirse sobre las vertientes metodológicas, técnicas y herramientas que tendrían que emplearse. En suma, los soportes científicos y la experiencia, así como las realidades arquitectónicas, que más allá de la dualidad entre las fachadas que expresan lo captado y adaptado de los modelos europeos (Mancero, 2010), deben viabilizar el potencial de la arquitectura local como una simbiosis de fuerzas culturales, sintetizada en una misma estructura (Municipalidad de Cuenca, 1998). Este panorama alienta a plantear una fase piloto para afinar la construcción lógica del proceso en los niveles de factibilidad para implementación, optimización y validación de la propuesta de articulación investigativa entre arquitectura y arqueología (ver Figura 7).

De este modo, para la definición de criterios de intervención, si bien la normativa vigente o la convención social y política del momento (Zafra de la Torre, 2017) constituyen el discurso patrimonial autorizado (Waterton y Smith, 2009; Barreiro, 2012), deben tomarse en cuenta aspectos que las experiencias internacionales demuestren como necesarios. Al considerar la arqueología urbana, la histórica o la colonial, la ejecución debe, a criterio de Alzate (2011), intentar avanzar hacia una renovada comprensión de los cambios culturales a lo largo del tiempo y, en el caso concreto del CHC, intentar esclarecer un período (p.e., entre los siglos XVI-XIX), desde las múltiples manifestaciones posibles, lo que evidenciaría la complejidad intrínseca del asunto. Desde otro campo, en la caracterización aplicada al componente cerámico de la arquitectura, a juicio de Lupión y Arjonilla (2010), es fundamental realizar pruebas in situ previas a la intervención para determinar la metodología específica y analizar su incidencia sobre la superficie. Los ensayos de idoneidad, reversibilidad y semejantes se incluyen en el proceso de contextualización del objeto patrimonial. Estos cometidos son referentes para subsiguientes investigaciones (Alzate, 2011) y podrán dar lugar a recomendaciones sobre cómo intervenir en función de los requerimientos del bien cultural.

\section{Conclusiones}

En la ciudad de Cuenca, con significativa y evidente riqueza cultural, la coexistencia disciplinar arqueología-arquitectura expone vicisitudes que limitan el conocimiento y la conservación patrimonial como, por ejemplo, la prevalencia en la excavación de una mirada disciplinar que desconoce las dimensiones sustanciales de la arquitectura; incluso cuando el propósito es recuperar un edificio patrimonial, se omite la investigación histórica. Cuando han existido intervenciones, los esfuerzos investigativos y conservacionistas desde la interdisciplinariedad solo han sido abordados desde la esfera pública, mientras que el sector privado ha visto acumular altas estadísticas de infracciones para evitar inversión económica y gestión administrativa adicional que resultaría de esa preocupación por el asunto histórico.

Convendría orientar el modelo territorial hacia planteamientos metodológicos con mayor fuerza y alcance temporal, que incluyan, además de la visión individual del monumento arquitectónico o arqueológico, la elaboración e implementación de planes de conservación preventiva y riesgo, planes de educación y difusión patrimonial ciudadana, programas de investigación desde la dualidad investigaciónacción, la definición e implementación de cartas arqueológicas o sistemas de inventario y catalogación de bienes rurales, urbanos y arquitectónicos asociados y otros con los cuales sea posible aproximarse a las múltiples facetas de la ciudad. A esto se debe sumar que un mayor conocimiento de los monumentos históricos, aunque poco compatible con las categorías de valor municipal, ampliaría las oportunidades de conocimiento y conservación de los bienes patrimoniales, porque no podría asegurarse que los bienes de valor ambiental y sin valor arquitectónico carecen de componentes arqueológicos; semejante asunción, ¿no supondría acaso desestimar el pasado protocańari, cañari e inca de estos territorios, e incluso de predios cuya distancia dio lugar a que la ciudad sea catalogada como Patrimonio Cultural de la Humanidad? En definitiva, parece pertinente apostar por conocer la ciudad también desde su visión como yacimiento, por incentivar el nivel de participación social, así como apoyar el fortalecimiento de la identidad cultural robusteciendo la 
gestión de los bienes patrimoniales. Igualmente esta propuesta investigativa asume como premisa la búsqueda de medios alternativos y complementarios, y los criterios específicos para la intervención monumental deben renovarse desde la convergencia de las políticas territoriales, la asistencia técnico-científica de la normativa y las experiencias internacionales.

\section{Referencias citadas}

AA.VV. (2015). Libro Blanco de la gestión del patrimonio histórico-arqueológico del grupo de Ciudades Patrimonio de la Humanidad en España. Madrid: Kultura.

Aguirre Ullauri, M. y Álvarez, A. (2015). Análisis históricoconstructivo de la iglesia de Santo Domingo de Guzmán (Pajarejos, Segovia) por medio del análisis estratigráfico constructivo. Maskana, 6(1), 131-148.

Alberto, V. (2008). La arqueología como herramienta histórica. En Gutiérrez, A. (Dir.). VI Congreso de Patrimonio Histórico: Arqueología de Canarias. Territorio y Sociedad. Lanzarote, España.

Alzate, A. (2011). La arqueología colonial como herramienta para contrastar la historia escrita. ArqueoWeb, 13, 4-14.

Appetechia, A., Brandt, O., Gardelin, G., Menander, H. y Tharén, H. (2014). New methods for building archaelogical documentation and analysis process. Report of work 2012. Swedish National Heritage Board. Suecia: Elanders Sverige AB.

Asamblea Nacional del Ecuador (2008). Constitución Politica del Ecuador. Montecristi, Ecuador.

Astudillo, D. (2012, febrero 13). Oficio No DAHP-02632012. (Inédito).

Azkarate, A. (2010). El análisis estratigráfico en la restauración del patrimonio construido. En De Vega, E. y Martín, C. (Dirs.). Actas del congreso Arqueología aplicada al estudio e interpretación de edificios históricos. Últimas tendencias metodológicas (pp. 51-63). Madrid: Ministerio de Cultura, Subdirección General Técnica de Publicaciones, Información y Documentación.

Barreiro, D. (2012). Arqueología aplicada y patrimonio: memoria y utopía. Complutum, 23(2), 33-50.
Beaundry, M. y Parno, T. (2016). Arqueologías de la movilidad: cruzando los límites espaciales y temporales. Vestigios. Revista Latinoamericana de Arqueología Histórica, 10(2), 5-24.

Benedet, V. (2012). La arquitectura colonial de Buenos Aires. Análisis historiográfico, balance crítico y nuevas herramientas para su estudio. Bibliograhica Americana, $8,1-32$.

Benjamin, W. (1992[1936]). The work of art in the age of mechanical reproduction. En Illuminations (pp. 211244). Londres: Fontana.

Buys, J., Domínguez, V. y Andrade, C. (1988). La investigación arqueológica en el Museo Fray Pedro Bedón, convento de Santo Domingo. En De Sutter, P. y Alemán, M. (Eds.). La preservación y promoción del patrimonio cultural del Ecuador (pp. 27-34). Quito: Instituto Nacional de Patrimonio Cultural.

Buys, J., Domínguez, V. y Zambrano, P. (1989). La arqueología de Cumbayá, provincia de Pichincha, Ecuador. En Bouchard, J. F. y Guinea, M. (Eds.). Relaciones interculturales en el área ecuatorial del Pacífico durante la época precolombina (pp. 75-95). Oxford: BAR International Series.

Buys, J., Domínguez, V. y Zambrano, P. (1990). Tercera fase de excavaciones arqueológicas en el claustro principal del convento de Santo Domingo, Quito. En Sutter, P. y Moscoso, F. (Eds.). La preservación y promoción del patrimonio cultural del Ecuador (pp. 13-19). Quito: Instituto Nacional de Patrimonio Cultural.

Caballero Zoreda, L. (1995). Método para el análisis estratigráfico en construcciones históricas o Lectura de paramentos. Informes de la Construcción, 46(435), 37-46.

Carpio, C. y Flores, F. (1996). Haciendas en el Azuay, sus casas y edificaciones (Tesis de grado). Universidad de Cuenca, Ecuador.

Choay, F. (2007). Alegoría del Patrimonio. Barcelona: Gustavo Gili.

Consejo Cantonal (2010). Ordenanza para la Gestión y Conservación de las áreas históricas y patrimoniales del cantón Cuenca. Ecuador. 
Criado-Boado, F. y Barreiro, D. (2013). El patrimonio era otra cosa. Estudios Atacameños. Arqueología y Antropologia Surandinas, 45, 5-18.

Doglioni, F. (2012). Arqueología: manteniendo la autenticidad en la arquitectura de Venecia. En Castillo, A. (Ed.). Actas del Primer Congreso Internacional de Buenas Prácticas en Patrimonio Mundial: Arqueología (pp. 102-115). Madrid: Editora Complutense.

Domínguez, L. y Funari, P. (2002). La arqueología urbana en América Latina: el caso de La Habana vieja, ciudad arqueológica. Estudios Iberoamericanos, 28(2), 113-123.

Fernández-Baca, R. (2014). 50 años de la Carta de Venecia: del monumento histórico y su conservación, al desarrollo sostenible. En López Morales, F. J. y Vidargas, F. (Eds.). Los nuevos paradigmas de la conservación del patrimonio mundial. 50 años de la Carta de Venecia (pp. 41-62). México: Instituto Nacional de Antropología e Historia.

Funari, P. (1994). South American Historical Archaeology. Historical Archaeology in Latin America, 17, 64-71.

Funari, P. (1996). Archaeology, History and Historical Archaeology in South America. International Journal of Historical Archaeology, 1, 137-148.

Funari, P. (2002). Arqueología Histórica en una perspectiva mundial. En Zarankin, A. y Senatore, M. (Eds.). Arqueología da Sociedade Moderna America do Sul: Cultura Material, Discursos e Práticas (pp. 107-115). Buenos Aires: Del Tridente.

Funari, P. (2015). Historia comparada en Iberoamérica: ciudades españolas y portuguesas en el nuevo mundo. Revista de História Comparada-Programa de Pós-Graduação em História Comparada-UFRJ, 9(1), 69-87.

Galarza, V. (2012). Estudio de Monitoreo Arqueológico para el Proyecto Arquitectónico Integral para el Nuevo Centro de Rehabilitación Social Regional. Fundación Municipal El Barranco. (Inédito).

García, G. (2015). Informe Infracciones Centro Histórico de Cuenca, Proyecto VlirCPM, Cuenca: Universidad de Cuenca (documento inédito).

Gilabert, X. y Mora, R. (2014). Métodos y técnicas de recuperación del registro arqueológico: una mirada desde el presente. Treballs d'Arqueología, 20, 3-5.
Gravano, A. (2018). Hacia una arqueología de lo urbano. Urbania. Revista latinoamericana de arqueología e historia de las ciudades, 7, 13-20.

Hicks, D., Horning, A. (2006). Historical Archaeology and Buildings. En Hicks, D. y Beaudry, M. C. (Eds.). The Cambridge Companion to Historical Archaeology (pp. 273292). Cambridge, MA: Cambridge University Press.

ICOMOS (1964). Carta de Venecia.

ICOMOS (1968). Carta de Noto.

ICOMOS (1984). El conservador-restaurador: definición de una profesión. Copenhague.

ICOMOS (1987). Carta de Washington.

ICOMOS (1990). Carta Internacional para la gestión del patrimonio arqueológico. Lausana.

Idrovo, J. (1993). Arquitectura y urbanismo en Tomebamba, Ecuador. Beiträge zur Allgemeinen und vergleichenden Archäologie, 13, 253-330.

Idrovo, J. (1998). Tomebamba: primera fase de conquista incásica en los Andes septentrionales. Los Cañaris y la conquista incásica del austro ecuatoriano. En Dillehay, T. y Netherly, P. (Eds.). La frontera del estado inca. Fundación Alexander von Humboldt. Quito: Abya-Yala.

Idrovo, J. (2000). Tomebamba. Arqueología e historia de una ciudad imperial. Cuenca: Ediciones del Banco Central.

Idrovo, J. (2008a). Inventario y catastro de inmuebles y sitios con valor arqueológico localizados en el Centro Histórico de Cuenca. Proyecto Inventario Catastral de Arqueología de Cuenca. Unidad de Arqueología Urbana (documento inédito).

Idrovo, J. (2008b). Informe histórico arqueológico sobre el colector El Gallinazo en su recorrido por la Plaza 9 de Octubre y recomendaciones para el uso social del bien cultural. Unidad de Arqueología Urbana (documento inédito).

Idrovo, J. (2008c). Informe de prospección arqueológica en el sitio casa del Dr. Pedro Córdova. Unidad de Arqueología Urbana (documento inédito).

Idrovo, J. (2010). Prospección Arqueológica en el sitio Icto Cruz, Cuenca-2010. (Propuesta técnica y económica para la realización de estudios) (documento inédito). 
Idrovo, J. (2012). Arqueología urbana: una práctica indispensable. Revista del Patrimonio Cultural del Ecuador, 2, 24-28.

Idrovo, J., Calderón, F. y Proaño, R. (2008). Informe de seguimiento y registro de los trabajos de sustitución de colectores antiguos. Unidad de Arqueología Urbana (documento inédito).

Idrovo, J. y Bacacela, I. (2008a). Informe de Prospección El Barranco-Av. 3 de Noviembre-puente El Vado. Unidad de Arqueología Urbana (documento inédito).

Idrovo, J. y Bacacela, I. (2008b).Informe. Prospección y excavaciones en Pasaje León. Unidad de Arqueología Urbana (documento inédito).

Idrovo, J. y Bacacela, I. (2008c). Prospección y excavación en la Calle Santa Ana. Unidad de Arqueología Urbana (documento inédito).

Idrovo, J. y Calderón, F. (2008a). Informe de prospección iglesia de San Francisco. Unidad de Arqueología Urbana (documento inédito).

Idrovo, J. y Calderón, F. (2008b). Informe de prospección Museo Remigio Crespo Toral. Unidad de Arqueología Urbana (documento inédito).

Idrovo, J. y Calderón, F. (2008c). Informe de prospección. Plazoleta de Santo Domingo. Unidad de Arqueología Urbana (documento inédito).

Idrovo, J., Calderón, F. e Idrovo, P. (2008). Informe de prospección Cementerio Municipal de Cuenca. Unidad de Arqueología Urbana (documento inédito).

Idrovo, J. y Campoverde, J. (2008). Informe de prospección Centro Comercial Popular. Unidad de Arqueología Urbana (documento inédito).

Idrovo, J. y Guamán, J. (2008a). Informe. Prospección y excavaciones en la iglesia de Todos Santos. Unidad de Arqueología Urbana (documento inédito).

Idrovo, J. y Guamán, J. (2008b). Prospección del sitio: Plaza El Otorongo. Unidad de Arqueología Urbana (documento inédito).

Idrovo, J. y Guamán, J. (2008c). Informe de prospección plaza e iglesia Cristo Rey. Unidad de Arqueología Urbana (documento inédito).
Idrovo, J. y Guamán, J. (2008d). Prospección del sitio: plaza El Otorongo. Unidad de Arqueología Urbana (documento inédito).

Idrovo, J. y Guamán, J. (2008e). Proyecto: Puente peatonal del Otorongo. Unidad de Arqueología Urbana (documento inédito).

Idrovo, J. y Guamán, J. (2008f). Informe de prospección escalinata y puente del Otorongo. Unidad de Arqueología Urbana (documento inédito).

Idrovo, J. y Guamán, J. (2008g). Informe de prospección plazoleta de El Rollo. Unidad de Arqueología Urbana (documento inédito).

Idrovo, J. y Maldonado, J. (2008a). Prospección arqueológica en el sitio: plazoleta Cruz del Vado. Unidad de Arqueología Urbana (documento inédito).

Idrovo, J. y Maldonado, J. (2008b). Informe de Prospección. Plazoleta de la Música. Unidad de Arqueología Urbana (documento inédito).

Idrovo, J. y Maldonado, J. (2008c). Informe de Prospección. Plazoleta de las Secretas. Unidad de Arqueología Urbana (documento inédito).

Idrovo, J. y Maldonado, J. (2008d). Informe de Prospección. Plazoleta Monroy. Unidad de Arqueología Urbana (documento inédito).

Idrovo, J. y Maldonado, J. (2008e). Informe de Prospección Casa Serrano. Unidad de Arqueología Urbana (documento inédito).

Idrovo, J. y Maldonado, J. (2008f). Prospección y excavación en la Calle Santa Ana. Unidad de Arqueología Urbana (documento inédito).

Idrovo, J. y Proaño, R. (2008a). Informe de Prospección. Plazoleta Monroy. Unidad de Arqueología Urbana (documento inédito).

Idrovo, J. y Proaño, R. (2008b). Informe de Prospección Arqueológica Plaza Gaspar Sangurima (Rotary). Unidad de Arqueología Urbana (documento inédito).

Idrovo, J. y Sancho, W. (2008a). Informe de Prospección El Barranco-Puente Roto-Escalinatas. Unidad de Arqueología Urbana (documento inédito). 
Idrovo, J. y Sancho, W. (2008b). Informe de Prospección calle Baltazara de Calderón. Unidad de Arqueología Urbana (documento inédito).

Idrovo, J. y Sancho, W. (2010). Informe de Prospección Arqueológica Plaza Gaspar Sangurima (Rotary).Unidad de Arqueología Urbana (documento inédito).

Instituto Nacional de Patrimonio Cultural (2008). Memoria Técnica Ictocruz sobre la casa ubicada en el terreno municipal (documento inédito).

Jamieson, R. (2003). De Tomebamba a Cuenca. Arquitectura y Arqueología colonial. Quito: Abya-Yala.

Jamieson, R. (2005). Colonialism, social archeology and lo Andino: historical archaeology in the Andes. Word Ar chaeology. Historical Archaeology, 37(3), 352-372.

Jamieson, R. (2014). Hacienda ruins as sites of difficult memory in Chimborazo, Ecuador. Journal of Social Archeo$\log y, 14(2), 224-243$.

Jaramillo, D. (2010). Informe de Extensión de terreno necesaria para la implantación del Centro de Rehabilitación Social de Mujeres y Varones de la Ciudad de Cuenca CRSMVC en el predio determinado por el Ilustre Consejo Cantonal (Inédito).

Kennedy, A. (2007). Apropiación y resimbolización del patrimonio en el Ecuador. Historia, Arquitectura y Comunidad. El caso de Cuenca. Procesos. Revista Ecuatoriana de Historia, 25(1), 129-151.

Lupión, J. y Arjonilla, M. (2010). La cerámica aplicada en arquitectura: hacia una normalización de los criterios de intervención. Geconservación, 1, 99-126.

Maestre, M. (2012). Arqueología: manteniendo la autenticidad en la arquitectura de Venecia. En Castillo, A. (Ed.). Actas del Primer Congreso Internacional de Buenas Prácticas en Patrimonio Mundial: Arqueología (pp. 436-449). Madrid: Editora Complutense.

Mancero, M. (2010). De Cuenca Atenas a Cuenca Patrimonio: estrategias de distinción en La construcción del Estado-Nación. En Burbano, F. (Coord.). Transiciones y rupturas. El Ecuador en la segunda mitad del siglo XX (pp. 197-246). Colección Bicentenario. Quito FLACSO.
Ministerio de Coordinación de la Política y Gobiernos Autónomos Descentralizados (2011). Código Orgánico de Ordenamiento Territorial y Descentralización. Quito: Ecuador.

Ministerio de Justicia, Derechos Humanos y Culto (2012). Propuesta técnica: Centro de Rehabilitación Social Regional Sierra Centro Sur (documento inédito).

Ministerio de Justicia, Derechos Humanos y Culto (2012a). Levantamiento técnico del inmueble municipal Icto Cruz (documento inédito).

Municipalidad de Cuenca (1983). Ordenanza para el Control y Administración del Centro Histórico de la ciudad de Cuenca.

Municipalidad de Cuenca (1998). Propuesta de inscripción del Centro Histórico de Cuenca, Ecuador en la lista de patrimonio mundial.

Querol, M. y Castillo, A. (2012). Arqueología preventiva y patrimonio mundial. El ejemplo espańol como base para el cambio en el ejercicio de la gestión arqueológica. En Castillo, A. (Ed.). Actas del Primer Congreso Internacional de Buenas Prácticas en Patrimonio Mundial: Arqueología (pp. 51-65). Madrid: Editora Complutense.

Rivadeneira, M. (2013). Arqueologia de rescate, patrimonio arqueológico y consumo del pasado en la construcción del nuevo Aeropuerto Internacional de Quito (Tesis de grado Antropología mención Arqueología). Quito: Pontificia Universidad Católica del Ecuador.

Schávelzon, D. (2002). El futuro del pasado. Indagaciones en arqueología urbana. En Alderoqui, S. y Penchanky, P. (Comps.). Ciudad y ciudadanos. Aportes para la enseñanza del mundo urbano. Cuestiones de Educación, 37 (pp. 199215). Argentina: Paidós Ibérica.

Scovazzi, E. (1996). Centros históricos y cultura urbana en América Latina. Ciudades, 3, 135-154.

Secretaría Nacional de Planificación y Desarrollo (2007). Plan de Desarrollo Nacional 2007-2010. Quito, Ecuador.

Secretaría Nacional de Planificación y Desarrollo (2009). Plan Nacional del Buen Vivir 2009-2013. Quito, Ecuador. 
Secretaría Nacional de Planificación y Desarrollo (2013). Plan Nacional del Buen Vivir 2013-2017. Quito, Ecuador.

Secretaría Nacional de Planificación y Desarrollo (2017). Plan Nacional de Desarrollo 2017-2020. Quito, Ecuador.

Segarra, V. (2016). Metodología para la documentación del Patrimonio Cultural Edificado de la ciudad de Cuenca (Tesis de Magíster en Conservación y Gestión del Patrimonio Cultural Edificado), Universidad de Cuenca, Cuenca.

Tabales R., M. (2002). Arqueología y rehabilitación en Sevilla. Desarrollo metodológico y práctico. Arqueología de la Arquitectura, 1, 193-206.

UNESCO (1956). Recomendación que define los principios internacionales que deberían aplicarse a las excavaciones arqueológicas. Novena Conferencia General. Nueva Delhi, 40-43.

Valdez, F. (2012). La investigación arqueológica en el Ecuador: Reflexiones para un debate. Revista del Patrimonio Cultural del Ecuador, 2, 6-23.

Vela, F. (2011). El desarrollo de la arqueología histórica en España. Algunas experiencias recientes en la ciudad de Madrid. Canto Rodado, 6, 75-115.

Vela, F. (2015). Urban Archaeology in Madrid. Experiencies and opportunities to understand the historical city. Esempi di Architettura, 2(1), 21-35.
Villalba, F. (2010). Informe del Proyecto. Investigación arqueológica en el área concerniente a la construcción del Centro de Rehabilitación Social de Mujeres y Varones de Cuenca (CRSMVC). (Inédito).

Waterton, E. y Smith, L. (Eds.) (2009). Taking Archaeology out of Heritage. Newcastle: Cambridge Scholars Publishing.

Zafra de la Torre, N. (1996). Hacia una metodología para el estudio del patrimonio arqueológico. Complutum. Extra, 6(II), 225-239.

Zafra de la Torre, N. (2017). El registro arqueológico como patrimonio histórico. Complutum, 28(1), 23-35.

Zarankin, A. y Salerno, M. (2007). El sur por el sur. Una revisión sobre la historia y el desarrollo de la Arqueología Histórica en la América Meridional. Vestigios. Revista Latino Americana de Arqueología Histórica, 1(1), 15-47.

\section{Otros}

Pla, R. (6 de marzo de 2017). Comunicación personal realizada vía correo electrónico. 